\title{
Autoria deslocada e audiovisualidades engajadas em "Bixa Travesty"1
}

Daniel Zacariotti ${ }^{2}$

Rose de Melo Rocha ${ }^{3}$

\footnotetext{
${ }^{1}$ O presente trabalho foi realizado como parte da pesquisa "Artivismo musical de gênero em São Paulo", com bolsa do Conselho Nacional de Desenvolvimento Científico e Tecnológico (CNPQ), e da dissertação de mestrado "Baseado em Carne Viva e Fatos Reais" subsidiada pela bolsa PROSUP/Taxa da Coordenação de Aperfeiçoamento de Pessoal de Nível Superior - Brasil (CAPES).

${ }^{2}$ Mestrando em Comunicação e Práticas de Consumo (ESPM-SP), bacharel em Artes Cênicas (UnB) e em Comunicação Social (UCB). Tem desenvolvido projetos relacionados à disseminação de novas narrativas voltadas à dissidência de gênero. Pesquisa corpo, documentário, gênero e audiovisual em Linn da Quebrada.

Email: danielzacariotti@gmail.com

${ }^{3}$ Professora titular do PPGCOM-ESPM, Líder do GP CNPQ Juvenália, Membro da coordenação ampliada do GT CLACSO Infâncias e Juventudes. Bolsista produtividade CNPQ.

Email: rlmrocha@uol.com.br
} 


\title{
Resumo
}

A partir da análise do documentário Bixa Travesty (2018), com roteiro dos cineastas cisgêneros Kiko Goifman e Claudia Priscilla e da atriz e cantora travesti Linn da Quebrada, com direção dos dois primeiros referenciados, problematizamos a ideia de espaço de autoria/espaço autoral e o engajamento da obra fílmica em uma perspectiva implicada, notadamente em relação aos regimes e políticas de audiovisibilidade articuladas por artivismos musicais e dissidências de gênero. Tem-se por pressuposto a compreensão do espaço do autor e do campo audiovisual como lugares de embate e disputas de poder; espaço este que, como aqui proposto, pode ser utilizado para percorrer um caminho de elucidação de uma possível autoria deslocada. Essa ideia de autoria deslocada, juntamente com a perspectiva de um cinema de sujeito, se daria de modo a ressaltar a potência narrativa do sujeito (re) apresentado - um caminho ético, estético e político de deslocamento de poderes. Em termos metodológicos, assumimos uma leitura expandida da produção audiovisual que considera as dinâmicas afetuais e políticas nela implicadas. Nossa chave de leitura, que é também uma perspectiva epistemológica, reconhece a centralidade do corpo na enunciação autobiográfica, na correlação com as audiências presumidas, e no próprio acionamento da materialidade fílmica.

Palavras-chave: Bixa Travesty; Linn da Quebrada; autoria deslocada; audiovisualidades engajadas.

\begin{abstract}
From the analysis of the documentary Bixa Travesty (2018), scripted by the cis filmmakers Kiko Goifman, Claudia Priscilla, and the travesti actress and singer Linn da Quebrada, directed by the first two, we problematize the idea of authorship/space of authorship and the engagement of the film in an implicated perspective in relation to the regimes and policies of audiovisibility, articulated by musical artivisms and gender differences. It is assumed that the authorial space and the audiovisual field are places of conflict and power disputes; this space, as proposed here, can be used to elucidate a possible displaced authorship. This idea of displaced authorship, along with the perspective of a subject cinema, would emphasize the narrative potency of the (re)presented subject - an ethical, aesthetical and political path to power displacements. In methodological terms, we use an expanded reading of the audiovisual production that considers the involvement of its affective and political dynamics. Our lenses to read the work, which are also an epistemological perspective, recognize the centrality of the body in the autobiographical enunciation, in the correlation with the assumed audiences, and in the activation of the filmic materiality.
\end{abstract}

Keywords: Bixa Travesty; Linn da Quebrada; displaced authorship; engaged audiovisualities. 


\section{Considerações introdutórias: pressupostos analíticos e objeto empírico}

Linn da Quebrada é talvez uma das mais expressivas representantes da vasta produção musical e audiovisual brasileira que, em especial na última década, consolida uma vertente artística capitaneada por juventudes LGBTQIA+ ${ }^{4}$. Com mais de 275 mil seguidores no Instagram ${ }^{5}, 80$ mil inscritos em seu canal do YouTube ${ }^{6}, 181$ mil ouvintes mensais no Spotify ${ }^{7}$ e 133 mil seguidores no Twitter $^{8}$, Linn é uma potência no cenário artístico do Brasil. Afirmando-se inicialmente como bixa travesti preta, Linn, de modo peculiar e com um manejo artístico bastante próprio, vai processualmente se apresentar publicamente a partir de um lugar de mulheridade, em sua própria denominação. Transitando por audiências segmentadas e por universos de seguidores fervorosos, não abandonou atuações territoriais periféricas, ocupando também espaços do mainstream televisivo. Assim, a investida na produção de um longa-metragem documental, que a teria como protagonista, despertou expectativas variadas.

Considerando o documentário "Bixa Travesty" partícipe da performance audiovisual e das políticas de audiovisibilidade articuladas por Linn e sua rede de aliadas/es/os, abordaremos alguns traços distintivos da ação comunicacional implicada na materialidade fílmica do documentário. "Bixa Travesty" é uma produção inserida na articulação entre visada biográfica e relatos sobre musicalidades brasileiras que, segundo Estevão (2019), marca a produção documental no Brasil desde a chamada "retomada do cinema nacional" nos anos 1990. Também notamos a vinculação de "Bixa travesty" ao boom dos "artivismos estéticos das dissidências sexuais e de gênero" (COLLING, 2018). É desde este marcador dissidente e artivista que o documentário se desloca da vertente mainstream (que privilegia retratos de cantores e cantoras consagrados), dirigindo sua intenção criativa a uma sujeita-artista que transita pelas margens indisciplinares e indisciplinadas da produção cultural.

A partir de uma análise audiovisual expandida, ancorada em um olhar localizado, em uma perspectiva de leitura multi-situada e considerando implicações históricocontextuais dos textos culturais, o presente artigo problematiza as ideias de "espaço de autoria/espaço autoral" e de "audiovisualidades engajadas" propiciadas pelo documentário "Bixa Travesty" (2018), com roteiro dos cineastas Kiko Goifman , Claudia

\footnotetext{
${ }^{4}$ Para uma análise específica de Linn da Quebrada, consultar Rocha e Rezende (2019) e Neves (2019). ${ }^{5}$ Fonte: https://www.instagram.com/linndaquebrada/. Acesso 01/09/2020.

${ }^{6}$ Fonte: https://www.youtube.com/channel/UCje0RwqumaW8Be1c1YKL7DA. Acesso 01/09/2020.

${ }^{7}$ Fonte: https://open.spotify.com/artist/5gGBopc7iw8yLqwxfPIv3t. Acesso 01/09/2020.

${ }^{8}$ Fonte:

https://twitter.com/linndaquebrada?ref src=twsrc\%5Egoogle\%7Ctwcamp\%5Eserp\%7Ctwgr\%5Eauthor. Acesso 01/09/2020.

${ }^{9}$ Nascido em Belo Horizonte, Kiko Goifman é antropólogo pela UFMG e Mestre em Multimeios pela UNICAMP. Tendo dirigido diversas obras de longa metragem, Kiko tem sua obra diretamente ligada ao gênero documentário, sendo em "Bixa Travesty" seu mais recente trabalho. É conhecido por sua
} 
Priscilla $^{10}$ e da atriz e cantora Linn da Quebrada ${ }^{11}$, direção dos dois primeiros referenciados e protagonismo narrativo performado por Linn.

Dialogando com o repertório da análise fílmica em seu sentido mais clássico, não a temos como principal eixo analítico. E isto não se dá por casuísmo, mas, sim, por compreendermos que o documentário é parte dos regimes de audiovisibilidade que articulam e acionam os três atores/autores de "Bixa Travesty", Linn, Kiko e Claudia. Ou seja, priorizamos neste recorte específico às possíveis dimensões contra hegemônicas, dissidentes e dissensuais que permitem atualizar o embate em torno da autoria justamente por isso, optamos pelo termo análise audiovisual expandida. Deste modo, nos aproximamos dos estudos sobre a cultura audiovisual em suas implicações políticas, situando historicamente o debate nas últimas décadas, nas quais ações protagonistas juvenis tomam para si o narrar e apresentar a si mesmos, buscando, como no caso estudado, parcerias criativas com o que nomeamos ações audiovisuais engajadas e partilhadas.

Como mostra Freire (2012), o espaço do autor é efetivamente um campo de lutas e disputas de poder. Em "Bixa Travesty", a oclusão voluntária de exclusividade autoral por parte dos diretores Kiko e Claudia é, claramente, um modo específico de se posicionar neste campo. Em nossa hipótese reflexiva, tal medida está associada a uma intencionalidade pactuada com a protagonista do documentário, de modo a evidenciar a narrativa autobiográfica e contestadora de Linn. Vida e obra borram suas fronteiras, assim como, na narrativa fílmica, as performances públicas da artista mesclam-se às tessituras cotidianas constituídas em sua intimidade com aqueles que a rodeiam.

Acionamos, neste aspecto, a crítica feita por Sontag (1987) ao "convencionalismo da interpretação" e ao sucateamento sensorial resultantes do excesso de interpretação e da fúria do desvelamento, bem como da sobrecarga sensológica com a qual lidamos cotidianamente. Analisar "Bixa Travesty" significa nos aproximamos da "superfície sensual da arte", de uma "erótica da arte" (SONTAG, 1987: 22-3) que tensiona a arte não pela via do que ela significaria, mas questiona o que ela realiza ou faz sentir. $O$

\footnotetext{
linguagem próxima ao filme ensaio e, atualmente, é, ao lado de Claudia Priscilla, diretor do talk show "TransMissão" apresentado por Linn da Quebrada e Jup do Bairro.

${ }^{10}$ Claudia Priscilla, cineasta e roteirista brasileira, é graduada em Jornalismo, estreou no cinema dirigindo o curta-metragem Sexo e claustro. Ganhou o prêmio de melhor filme e melhor direção no Festival de Paulínia com seu filme Leite e ferro, também vencedor do prêmio de melhor longa no Femina. Juntamente com Kiko Goifman dirigiu os longas Amapô, Olhe pra mim de novo e "Bixa Travesty". Sua obra é marcada por narrativas que discutem questões de sexo e gênero.

${ }^{11}$ Natural de São Paulo, Lina Pereira, mais conhecida por seu nome artístico Linn da Quebrada, é uma atriz, cantora, apresentadora, roteirista e compositora brasileira. Linn se apresenta como médica e monstra de si mesma. Celebrada por sua força artística e política disruptiva, Linn é uma das artistas mais relevantes do cenário musical dissidente de sexo e gênero do Brasil - tendo suas principais produções ligadas ao seu álbum Pajubá - e os clipes provenientes desse álbum -, o documentário "Bixa Travesty", o talk show "TransMissão" e a série "Segunda Chamada" (Rede Globo).
} 
documentário, texto cultural e materialidade fílmica, seria um lugar a um só tempo cronológico e sensológico, onde sentimos o tempo e temporalizamos as sensações. Esta analítica sensorial e "cronossensológica" (ROCHA, 1998) nos serve de inspiração epistemológica, remetendo igualmente a uma chave enunciadora que entendemos ter sido adotada na forma de feitura do documentário analisado.

A análise audiovisual expandida é tripartite, agregando dimensões técnicas/ sociotécnicas, filosóficas e antropológicas. O texto audiovisual documental, como espaço de disputa por sentidos e sentires, remonta à constituição do olhar como lócus de poder, sinalizando um modo de se posicionar - sujeitos realizadores e sujeitos (re)presentandos - ante dinâmicas de reconhecimento, objetificação, representação exógena, exotização e dominação do Outro. Toda uma antropológica audiovisual é também aí articulada: indagamos sobre o acionamento imaginário e sociotécnico que correlaciona o produto audiovisual e sua estrutura a marcadores históricos, mas que evoca, como antropo-experiência, cartografias de um sensível arcaico, imemorial.

Deste modo, ao problematizar a "não presença do autor" - ou, melhor dizendo, de uma autoria única versus a localização dos lugares de fala - a voz do diretor como "não presença subentendida" seria em si um posicionamento de condução, articulada de modo a dar centralidade à potência criativa da sujeita apresentada. Neste sentido se dá a aproximação deste documentário à ideia de uma "não-autoria aliada", perpassando uma potencial ampliação da audiovisibilidade protagônica de corpos considerados "outros" de um ponto de vista normativo, heterocentrado, cis-enquadrado, racista. Localizamos, na feitura do documentário, a perspectiva de construção de um comum que destaca os corpos invisibilizados e estigmatizados, os quais ganham, em primeiro plano, presença tátil e vocalizada no corpo fílmico. A escrita do desejo da narradora Linn trespassa os marcadores autorais que se poderiam associar à presença tutelar de um direcionamento externo explícito, atuando na modulação dos registros.

Não por acaso, é a mobilidade de Linn em sua diáspora urbano-midiática por shows, gravações, interiores domésticos com amigos e a mãe, que constrói, como uma linha plástica, a estrutura da narrativa fílmica. Em sinergia com este eixo de trânsito e plasticidade, a narrativa de Linn sobre si mesma evidencia mais um importante plot do documentário. Esta anamnese biográfica pontua, em diversos momentos, o filme, como em passagens tocantes em que a protagonista apresenta ao registro fílmico sua relação com as outridades de gênero que, um dia, a compuseram, como quando dialoga com sua anterioridade Lino.

"Bixa Travesty" explora como ponto de tensão parcializar e localizar o espaço de autoria em uma obra onde os diretores se despem da pretensão de exclusividade autoral para dar visibilidade ao outro socialmente invisibilizado, assumindo-o igualmente como 
autor e roteirista. A perspectiva dos "saberes localizados" (HARAWAY, 2009), grifando o espaço de onde o saber foi produzido, nos auxilia na identificação do sentido de se recusar a visão do autor/diretor como "dono da obra". Esta é também a ideia de Jean Baudrillard (1996) quando argumenta que a teoria deva ser um crime perfeito - uma teoria justa seria aquela em que o pesquisador/autor se mostra capaz de dar tamanha visibilidade para o sujeito ou objeto analisado que ele mesmo acabaria se tornando "menor".

Neste aspecto, aproximam-se texto fílmico e texto científico; corroborando o questionamento do monopólio da instância do saber/ver/ser pela figura do autor, valorizando, ao contrário, os espaços de coletividade autoral. Vemos que, como traz Vidarte (2019), as lutas por justiça social - e, neste caso, essas lutas se dão tanto através do documentário, quanto da pesquisa em si - devam se pautar pela horizontalidade, criticidade e por perspectivas que recusam ser depreciativas.

\section{Autoria deslocada no documentário}

Adentrando nas questões específicas do documentário, primeiramente localizamos o gênero documentário, especialmente os documentários engajados - como é o caso do aqui estudado -, como um gênero fílmico próximo à categoria audiovisual desenvolvida por Linda Williams (2004), chamada de "gêneros do corpo"12. Como mostra Gaines (1999), a partir do conceito de political mimesis,

[a] political mimesis começa com o corpo. Na verdade, tratase de uma relação entre corpos em dois locais - na tela, na plateia - e é o ponto de partida para a consideração do que um corpo faz o outro fazer. Inspirado na discussão de Linda William sobre os três gêneros que "fazem o corpo fazer coisas" (horror te faz gritar, melodrama te faz chorar e pornografia te faz "gozar"), o conceito de Mimese Política aborda o que é que o documentário quer que façamos. Embora possamos não querer defender o documentário radical como um gênero do corpo, ainda precisamos pensar o corpo em relação aos filmes que fazem o público querer chutar e gritar, filmes que os fazem querer fazer algo por

\footnotetext{
${ }^{12}$ Classificação desenvolvida por Linda Williams (2004) que define os tipos de produção cinematográfica que mobilizam os corpos dos espectadores a reagir de maneira sensória e sentimental, sendo elas: pornografia (faz o espectador gozar), o melodrama (faz chorar) e o horror (faz gritar).
} 
causa de condições no mundo do público. ${ }^{13}$ (GAINES, 1999:

90, tradução nossa)

Assim, o gênero do documentário é esse espaço que faz com que a audiência se movimente, ou melhor, que causa reverberações na audiência a partir da (re)apresentação ${ }^{14}$ mediada de um recorte do real na tela. Porém, de onde surge e como se dá essa (re)apresentação em "Bixa Travesty"?

Seguindo as colocações de alguns autores em relação ao gênero documentário, a narrativa e a construção da imagem perante a tela adviriam convencionalmente da ótica exclusiva do diretor/autor/criador. O autor-diretor, que no caso estudado seria convencionalmente representado por Kiko Goifman e Claudia Priscilla, com seu poder de decisão sobre a captação e edição das imagens, teria então controle sobre a narrativa e sobre o sujeito (re)apresentado. Tal aspecto é apontado nos escritos de Freire (2012) sobre os documentários etnográficos:

Há, portanto, na realização de todo documentário, uma relação de poder em que o realizador, queira ele ou não, detém o domínio sobre um processo em construção, enquanto as pessoas filmadas a ele são submetidas (FREIRE, 2012: 31)

Como vimos há pouco, ao deter o controle sobre a montagem, o realizador detém o controle sobre o produto final; mesmo que a escolha dos elementos que vão dar forma à sua mise en scène, mesmo que as relações com os sujeitos filmados tenham sido marcadas por eventuais conflitos de interesse, raramente isso aparece no filme, pois tudo pode ser elidido na montagem. Um documentário é quase sempre, portanto, o resultado de uma relação de poder, cujo produto final é o emblema da supremacia do realizador nessa relação

(FREIRE, 2012: 32)

\footnotetext{
${ }^{13}$ Do original: "Political mimesis begins with the body. Actualized, it is about a relationship between bodies in two locations - on the screen in the audience - and it is the starting point for the consideration of what the one body makes the other do. Inspired by Linda William" discussion of the three genres that "make the body do things" (horror makes you scream, melodrama makes you cry, and porn makes you "come"), the concept of political mimesis addresses what is that the committed documentary wants us to do. Although we might not want to make a case for the radical documentary as a body genre, we still need to think the body in relation to films that make audience members want to kick and yell, films that make them want to do something because of the conditions in the world of the audience."

14 Utilizamos o termo (re)apresentação a partir das ideias de Adriana Amaral, Camila Barbosa e Beatriz Polivanov (2015) onde elas mostram a (re)apresentação como uma abordagem entre a apresentação e a representação. Um termo que nos ajudaria a entender a realidade como apresentada e presentificada a partir de um outro olhar, redefinida, no nosso caso, o olhar do documentário.
} 
O documentário seria então um espaço unilateral de investigação, participação e (re)apresentação da vida do(s) sujeito(s) retratados monopolizado pelo autor-realizador. Essa perspectiva não só transforma o sujeito (re)apresentado em "propriedade" do autor, que de certa forma o objetifica. Além disso, este tipo de criação unidirecional pode alimentar uma recepção passiva e parcial, limitando o encontro entre documentário e o corpo espectador. Em "Bixa Travesty", o documentário afasta-se voluntariamente do monopólio narrativo por parte do autor-diretor, sendo este afastamento criado, principalmente, pela ênfase na potência de vida de Linn da Quebrada - a narrativa, a imagem. O corpo, a voz e os discursos trazidos por Linn durante o documentário provocam um deslocamento do espaço de autoria, que é atraída para a sujeita (re)apresentada e seus pares. É este um dos recursos para que o espaço de autoria seria transformado em uma partilha de autoria, ou, ainda, constituir uma autoria deslocada e multi-situada.

Também se podem visibilizar práticas cinematográficas que consideram que 0 documentário deva ser um espaço de coletividade e não de monopólio por parte do autor-realizador. Como pontuado por Marconi (2020), ao tratar dos escritos de Dyer (2002) e outros pensadores quanto à quebra criada pelas autorias de cineastas gays e lésbicas no escopo conceitual das autorias tradicionais, nota-se uma possibilidade de deslocamento a partir das potências de sujeitos dissidentes de sexo e gênero. Seguindo seus argumentos, temos que

[...] as noções tradicionais de autoria exercem [...] a função de fixar uma interpretação particular, autoritária, antidemocrática e individualista do processo de construção fílmica. E, ao compartilhar desta noção de autoria pouco afeita à autocrítica, as artes e o cinema sustentaram, até muito recentemente, a valorização do indivíduo sobre o social e, na prática, o homem heterossexual cisgênero, branco e privilegiado como expoente máximo da figura do autor. Então seria necessário, como também já apontou Michael Peixoto (2014), um esforço reflexivo para ir além da figura do autor enquanto uma tipificação monarca e única fonte geradora de sentidos (como queria o romantismo); ou como um sistema de códigos articulados coerentemente (como acreditou o estruturalismo); nesse caso, também cabe rearticular a noção de autoria unicamente enquanto um "plano do artista" que deveria ser reconstituído pelo espectador (no caso das 
vanguardas) ou como "universo metafísico" que deve ser desvendado pela crítica (na "política dos autores"); e tampouco caberia aceitar a morte do autor nos termos de Roland Barthes (2004). (MARCONI, 2020: 17)

Em sentido similar, "Bixa Travesty" sugere uma quebra do espaço de monopólio da autoria por parte de realizadores/diretores brancos e cisgêneros, não só pela simples potência da sujeita (re)apresentada, mas também pela ruptura provocada pelas dissidências de gênero, sexo, raça e classe, performadas pela presença pública de Linn da Quebrada para além dos limites fílmicos. A partir desse afastamento máximo do autor como homem heterossexual cisgênero, branco e privilegiado, evideciado por Marconi (2020), é possível novamente identificar o deslocamento da autoria, assumindo-se como retaguarda da narrativa protagônica.

Poderíamos dizer, de maneira provocativa, que "Bixa Travesty" leva a um deslocamento de um cinema de autor para um "cinema de sujeito" ou ainda "cinema de subjetivação". Um cinema de sujeito/subjetivação seria aquele que reforça a emergência da personalidade e da subjetividade do (re)apresentado, aquele onde a narrativa de vida se sobrepõe às marcas de direção, um cinema feito para rasurar os escrutínios autorais monopolizados por uma direção impositiva. Importante marcar que ao propormos a passagem de um cinema de autor para um cinema de sujeito/subjetivação não temos 0 objetivo de antagonizar dentro da relação audiovisual sujeitos realizadores e sujeitos (re)apresentados. O aqui denominado sujeito (re)apresentado protagonista da imagem, aquele que move a subjetivação do material fílmico, precede a mobilização audiovisual exercida pela direção. Este sujeito protagônico, a partir de uma potência incorporada, seguindo Taylor (2003), forçaria uma prática de autoria multi-situada e deslocada. Para compreender as condições de possibilidade desse cinema alguns fatores podem ser destacados.

O primeiro deles, como aqui já apresentado, é a potência auto-poética de Linn da Quebrada; Linn se mostra como essa sujeita que, por sua mobilização prévia e controle técnico, estético e narrativo de materiais audiovisuais, reinventa a partilha autoral, seguindo Rancière (2009). Em segundo lugar, podemos trazer as alianças evidentes dentro do documentário entre Kiko, Claudia e Linn. A partir da relação construída entre aqueles que seriam tradicionalmente os principais detentores do processo do documentário, a história de Linn da Quebrada se faz mais presente do que as marcas da direção feita por Kiko e Claudia. Ou seja: Linn é abraçada pelo processo documental, de modo que sua narrativa seja o motor para uma direção aliada. Acreditamos que esta intencionalidade pactuada remete a um objetivo de disseminação de discursos e 
imagens dissidentes por parte dos três sujeitos aqui trazidos, ou seja, os três, em prol de uma ideal comum, geram uma prática multi-situada da autoria.

Sendo assim, a partir do processo observado em "Bixa Travesty", podemos definir a autoria deslocada - e multi-situada - como a ação de oclusão voluntária e consciente do autor-realizador a partir da potência do sujeito (re)apresentado, a qual possibilita a criação de um cinema de sujeito/subjetivação, portanto, o sujeito que ocuparia tradicionalmente o espaço de direção da obra é colocado/se coloca em segundo plano para catalisar a narrativa dissidente. Esta ação, que não exclui divergências ou tensionamentos entre sujeito e realizador, potencializa os efeitos disruptivos da obra e amplia a visibilidade autoral de corpos dissidentes, perpassando uma revisão da partilha desejante do visível e do sensível de modo a chegar a uma partilha ética entre sujeito protagônico e sujeito aliado. Deste modo, a partir do entendimento de Rancière (2009) quanto à partilha do sensível, a autoria deslocada promoveria uma redistribuição do mundo comum através da potencialização da narrativa do sujeito dissidente (re)apresentado na obra.

Porém, apesar de a autoria deslocada se mostrar como um caminho positivo de fuga em relação às exclusividades e aos privilégios do status de autor-realizador, ela cria um tensionamento em relação às pesquisas contemporâneas que valorizam a localização do espaço de autoria, como nos traz Haraway (2009):

Precisamos aprender em nossos corpos, dotados das cores e da visão estereoscópica dos primatas, como vincular o objetivo aos nossos instrumentos teóricos e políticos de modo a nomear onde estamos e onde não estamos, nas dimensões do espaço mental e físico que mal sabemos como nomear. Assim, de modo não muito perverso, a objetividade revela-se como algo que diz respeito à corporificação específica e particular e não, definitivamente, como algo a respeito da falsa visão que promete transcendências de todos os limites e responsabilidades. (HARAWAY, 2009: 2021)

Nos perguntamos então como a opção por uma autoria deslocada, que promove o documentário como um espaço de encontro, processualidade e imprevisibilidade, se posiciona frente à demanda por localização - espacial, temporal, social e cultural - do sujeito-autor. Como ressaltar o posicionamento de corporificação do autor em espaços onde o deslocamento e a aliança se tornam as matrizes mesmas da autoria? E ainda, seguindo a lógica de Baudrillard (1996) de que, para que um crime (teoria, obra, ação) seja perfeito, o autor deva desaparecer de modo a toda a evidência ser fixada sobre o 
fato executado, como podemos pensar uma obra perfeita sem perder a localização da mesma e de seus realizadores para com o mundo?

Ao não estabelecer uma autoria única para a obra, deslocando-a de uma condição de exclusividade do sujeito realizador para aliá-la ao sujeito (re)apresentado, o documentário se estrutura como materialidade tecida por todos aqueles que ocupam lugares de poder dentro da narrativa; desestabilizando o monopólio discursivo do realizador, a obra se plurivocaliza. A ideia do sujeito-autor subentendido ou ocluso não significa desconhecer sua potência e presença subjetiva na criação do documentário: ela é apenas deslocada de maneira a transformar a relação de poder de uma supremacia para uma aliança. Nesse aspecto, a autoria deslocada se aproxima dos pensamentos de Haraway (2009), com uma fuga da transcendência generalizante na busca de aliança com corporificações específicas e encarnadas. Todo um alinhamento ético-estético está aí implicado, impactando a condução das audiências ao encontro deste corpo fílmico aliado e implicado, prática cinematográfica e epistemológica substanciada na proposição de um cinema de sujeitos e subjetivações.

\section{Audiovisibilidades engajadas no documentário}

Um candente debate, que mobilizou cineastas e intelectuais brasileiros nos anos da década de oitenta, dava conta do lugar angustiante assumido por aqueles que buscavam, retomando um traçado histórico de vinte anos, se colocar ao lado do "povo", das minorias e dos desvalidos, mas não queriam incorrer em recuos populistas, menos ainda se filiar a projetos estatais que se apropriaram do "popular" para forjar um "nacional" de todo elitista, pastoral e hierárquico. É interessante cotejar a ideia de autoria deslocada e multi-situada e de cinema de sujeito/subjetivação desde a qual nos aproximamos de "Bixa Travesty" mediante a análise de alguns dos dilemas e das saídas encontradas por pensadores/realizadores que, historicamente, se confrontaram com embates similares; visto que, apesar de existirem estudos referentes à questão da autoria no documentário, nosso objetivo esteja intimamente ligado a uma abordagem voltada a sujeitos de audiovisibilidades engajadas, ou seja, retomamos perspectivas que se aproximam não do realizador que fala em nome do povo mas do povo que domina a linguagem audiovisual. Desta forma, seguindo os apontamentos de Rocha (2016), trazemos aproximações que mobilizem o corpo, e a prática incorporada, como instrumentos de implicação audiovisível.

Jean-Claude Bernardet, em três de suas obras seminais (BERNARDET, 1982; 1983; 1985), uma delas em coautoria (BERNARDET e GALVÃO, 1983) com Maria Rita Galvão, aborda aspectos desta relação "implicada" entre cineastas e as imagens produzidas. Deste amplo e complexo cabedal analítico recorremos a alguns argumentos 
nodais. Em primeiro lugar, indicamos revisitar a análise que Bernardet faz do documentário de curta metragem brasileiro produzido entre os anos 1960 e 1980, para indicar o destaque dado ao caráter de observatório sociocultural que tais produções revelariam. E isto ele não o faz de modo despretensioso ou diletante. Bernardet foca sua análise justamente na identificação, no seu, como diz, corpo-a-corpo com a obra, de "quem era o dono do discurso" (BERNARDET, 1985: 9). Em segundo lugar, destacamos a análise feita pelo autor do chamado "modelo sociológico" que indicava todo um esforço de documentaristas, desde a década de 70, em buscar linguagens e recursos estéticos de caráter experimental, resultando em "documentários inquietos", que reverberavam suas opções ideológicas, ou seja, que demarcaram o mais claramente possível de que lado eles estavam.

Neste ponto de nosso argumento, gostaríamos de indicar traços de união entre as perspectivas narrativas de Linn e os campos de atuação privilegiados pelos diretores do documentário. Kiko Goifman é conhecido por seus trabalhos no âmbito do documentário e da ficção. Suas narrativas são marcadas por cenas de marginalidade, abandono e dissidências; com forte influência dos trabalhos de Eduardo Coutinho e Jean-Claude Bernardet, costuma trazer temas da antropologia social para a tela através de elementos de dramaticidade. Tem Valetes em Slow-Motion, 33, Filmefobia e "Bixa Travesty" como seus mais relevantes trabalhos; trabalhos estes que tratam, em ordem, sobre o cotidiano em uma prisão, a busca do documentarista pela mãe biológica, a exposição de pessoas com patologias fóbicas a seus elementos de temor e, por fim, da vida da artivista Linn da Quebrada.

Claudia Priscilla é documentarista e tem sua trajetória marcada por narrativas ligadas às feminilidades. Seu primeiro longa-metragem, o documentário Leite e Ferro, versa sobre a maternidade na prisão a partir de um Centro de Atendimento Hospitalar à Mulher Presa. Dirigiu também Vestido de Laerte e Olhe para mim de novo - seu primeiro título em parceria com Kiko Goifman -, ambos documentários que trazem as vidas de sujeitos trans* ao protagonismo. Por fim, juntamente com Kiko, Claudia assina a direção de "Bixa Travesty".

As proposições de Jean-Claude Bernardet nos indicam uma aproximação implicada e informada do documentário ora problematizado, oriundo dos anos 2010, com a voz protagônica de uma bixa preta travesti, paulistana, artivista periférica e com lastro midiático, tendo na retaguarda uma dupla implicada e inquieta de cineastas. Assim, consideramos esta análise uma empreitada tanto ideológica quanto estética, a qual, para os termos de nossa interpretação, faz-se determinante. Ora, Bernardet, ao longo de sua trajetória de aproximação analítica de um conjunto de 21 filmes (BERNARDET, 1985), explora justamente o que também, nos limites cerrados de um pequeno artigo, 
desejamos fazer. Perguntado se, ao fim e ao cabo, sobre a disposição do documentarista em colocar-se em condição rasurada de autoria e se deslocar de uma superioridade hierárquica de fala, Jean-Claude nos oferece importantes pistas para um "corpo-a-corpo" com "Bixa Travesty" mais atento às formas e às performances estéticas apresentadas do que propriamente aos conteúdos por assim dizer tematizados.

Entendemos que este debate se atualiza, igualmente, com as discussões em torno da ideia de "cinema ativista", ganhando, na atualidade, ênfases específicas que abordam uma possível vertente decolonial em determinadas agências cinematográficas. Inquestionável, em "Bixa Travesty", a importância de se situar o contexto em que se insere, qual seja da guinada identitária e da nova volta no parafuso dos debates sobre subjetividades, diversidades e dissidências sexuais e de gênero. Ou seja, o documentário remete, embora de modo muito próprio, ao boom artivista de gênero (COLLING, 2018) do qual Linn é icônica referência:

A análise de corporeidades e circuitos culturais juvenis em contextos tardo-globalizados tem demandado formas de compreensão que não aquelas de base essencialista, canônica ou imutável. Essa mirada epistemológica aproximase, em nossa compreensão, da dinâmica mesma de algumas práticas juvenis contemporâneas, especialmente aquelas protagonizadas por jovens marginalizados, dissidentes e estigmatizados e que, enfrentando a subalternidade da subalternidade, questionam, invertem e subvertem as lógicas normativas de gênero e sexualidade. Essa juventude lança luz a outros modos de re-existência, cuja pluralidade de sentidos é viabilizada pela experimentação de corpos em transe e em trânsito, que se apropriam de e politizam/polinizam narrativas midiáticas, experiências do entretenimento e da cultura pop. (ROCHA e REZENDE, 2019: 26)

Como proposto em análises anteriores sobre as condições da crítica do audiovisível em tempos de hipervisibilidade e excitação sensorial (ROCHA, 2019), auscultamos a cena audiovisual articulada por artistas da cultura pop ligados a performances de gênero, perguntando, com Jacques Rancière (2009, 2012), sobre as possibilidades espectatoriais de engajamento que trespasse um viés mimético ou, para ser mais fiel ao autor, que indique perspectivas de emancipação do vidente. Recordemos: "A emancipação", diz Rancière (2012: 17), "começa quando se questiona a oposição entre 
olhar e agir, quando se compreende que as evidências que assim estruturam as relações do dizer, do ver e do fazer pertencem à estrutura da dominação e da sujeição".

Se seguirmos Omar Rincón (2006) em sua análise das narrativas do entretenimento, percebemos com o autor as narrativas em sua dimensão utópica, ressignificando o que pode ser lido como precário. Rincón argumenta ainda sobre a necessidade de se compreender tais narrativas de dentro, atentando para o fato de que a comunicabilidade está muito mais nos modos de narrar e na estrutura dos relatos do propriamente nos conteúdos. Assim, as culturas do entretimento constroem redes de significados coletivos de caráter público que nos falam de regimes afetuais, da invenção de um sujeito e da estetização do comportamento público (Cf. RINCÓN, 2006).

O pilar fundante das teorias da afecção (SPINOZA, 2008), permite-nos entender a dimensão em essência política do que nos é dado a ver, via a profusão de imagens visuais, e, o que particularmente interessa ressaltar, leva-nos a questionar aquelas que, ao nos afetarem, efetivamente aumentam ou diminuem nossa competência corpóreacognitiva de ação. É interessante neste aspecto resgatar Safatle (2008), quando chama atenção para leituras que associam as políticas de reconhecimento a "uma espécie de conceito meramente compensatório" (SAFATLE, 2008: 86, grifo nosso). Todavia, ele também observará outros enfoques, para os quais "as discussões sobre diferenças culturais e identidades sociais não mascaram necessariamente problemas estruturais ligados a lutas de redistribuição de riquezas entre classes" (SAFATLE, 2008: 87).

Na perspectiva de Stuart Hall (2002) toda uma economia identitária é revelada por textos culturais e, nesta perspectiva, ler os textos da cultura implicaria considerar as assimetrias das relações de poder que neles se refletem e retratam. A emergência de "devires minoritários" e cosmopolitas perpassam a cultura da mídia - e, diríamos, o mainstream e as cenas audiovisuais de resistência - com a geração do que o autor identifica como uma vasta e complexa iconografia identitária. Novamente, advogar, como faz o autor, a centralidade da cultura como referencialidade da existência nos permite compreender a constituição do campo estético e da experiência estética em sua estreita vinculação a disputas de poder, notadamente, ainda segundo Stuart Hall (2002), com a emergência e o trânsito de alteridades e outridades para o núcleo das cenas hegemônicas.

Embora documente vozes de dissidências sexuais e de gênero (COLLING, 2018) emitidas por juventudes oriundas e tributárias de uma vivência periférica (ROCHA, 2016) - as quebradas paulistas referendadas no próprio nome de Linn - "Bixa Travesty" não recorre em momento algum a uma estética ou entonação popularesca. Intimista e tátil, é de fato um filme de narrador. E Linn não é uma narradora qualquer. Erudita (uma das primeiras no Brasil a incorporar termos como "re-existência" e "corpo político" na 
apresentação de si), irônica e autorreflexiva (quando, por exemplo, narra, no documentário, a Lino, sua vida no passado e no masculino), esteticamente sofisticada (algo que ressoa, claramente, nos jogos de palavras e de imagens que estruturam suas músicas e videoclipes), Linn é emblemática da potente intelectualidade juvenil forjada, nas últimas décadas, nas periferias paulistas. Esta intelectualidade artivista, que pôde desfrutar de algumas experiências de formação cultural públicas, como as escolas livres de teatro e os pontos de cultura, domina também linguagens e repertórios de produção artística, algo que efetivamente se beneficiou do acesso a tecnologias e a redes de colaboração intergrupais.

A câmara que acompanha/desvela Linn é cúmplice deste olhar multifacetado no qual a crítica social alia-se à autorreflexividade existencial. Cidade, bairro, espaços de shows e de gravação, casa, corpo, ambos são marcadores estruturais de um modo de olhar, para si, para os outros e para o mundo. A câmera que se deixa guiar pelos corpos da cidade e pelos corpos de Linn, de sua mãe, de seu grupo de amigos é também aquela que trespassa os limites da exposição pública, olhando sem lascívia e sem temor para o corpo nu da bixa travesty, essa mulher "com peito e pau de mulher".

Vieira Jr. (2020), em livro recém-publicado, propõe repensar a ideia de "cinema do corpo" a partir de uma perspectiva do "realismo sensório". Para tanto, aciona reflexões sobre os corpos na vida cotidiana e no fluxo das urbanidades, propondo uma visada tátil nesta analítica corpo-narrativa da produção fílmica. O relato audiovisual articulado pela tessitura fílmica e pela tessitura corpóreo-narrativa de Linn remete assim a um modo de viver a cidade em suas bordas e brechas e, neste aspecto, evoca as estratégias de existência e as variadas formas de resistência que vêm sendo articuladas por "artivismos musicais de gênero" na contemporaneidade (ROCHA. 2016; 2018). Notamos, assim, que a urbanidade é uma imagem imaginada cujas territorialidades são uma citação evocada pelos traçados de Linn, corpo político público e privado, exposto em performances ao vivo e tecnologicamente mediadas, exposto, para a câmera, também nas experiências da intimidade doméstica, das amizades e da relação materna.

Deste modo, "Bixa Travesty" nos serve de observatório a partir do qual se podem indagar algumas das condições de emergência do artivismo musical de gênero (ROCHA, 2018) como categoria analítica relevante para se pensar não apenas a produção cultural das juventudes urbanas e periféricas de São Paulo, onde Linn se situa, mas também para compreender a ação política juvenil feita com e a partir de corpos expressivos e audiovisíveis, que agenciam, esteticamente, uma ética de existências possíveis, inteligíveis, que não apenas importam (BUTLER, 2019) mas que também portam materialidades corpóreas com potência política colocada em discurso audiovisível. 
O relato autobiográfico de Linn e dos seus evoca momentos chave deste existir, que se pensa do hoje (relatado por meio de imagens e audiovisualidades) para o passado (rememorado pelo próprio narrar protagônico), projetando presente e futuro. Não por acaso, a performance pública e a vida privada são marcadores narrativos recorrentes na composição fílmica, fronteiras que, em alguns momentos, são borradas por Linn. Analisando narrativas biográficas juvenis, Serrano Amaya (2004) propõe ler a juventude

como uma série de práticas discursivas que atuam em dois sentidos: (1) como uma forma em que cultural e historicamente se estabelecem modos particulares de ser em relação com o curso do tempo nas biografias dos sujeitos, e (2) como uma forma de organizar a reprodução social, particularmente a sua inserção nela. (...) Ao falar de "as e os jovens" farei alusão às formas em que tais processos se concretizam em sujeitos particulares, sujeitos localizados em relações sociais específicas, com histórias de vida encarnadas em certas corporalidades". ${ }^{15}$ (AMAYA, 2004: 46, tradução nossa)

A história de vida encarnada por Linn vem de uma corporalidade transformada, subjetividade trans, travesti, mas, igualmente, abriga uma expressão identitária que afirma sua mulheridade ao mesmo tempo em que ressalta a condição de bixa preta. Analisando "subjetividades trans em resistência", Escobar (2013) aponta que a "incursão da cena trans como parte da ação política busca não apenas fortalecer a identidade das implicadas, mas, sobretudo, transformar as concepções culturais sobre o trans nas comunidades a que se chega" ${ }^{16}$ (ESCOBAR, 2013: 146, tradução nossa).

O corpo de Linn mira a câmera, assim como a câmera mira o corpo de Linn. Neste contrato de apresentação e de leitura, o vidente é interpelado pela proposta de um duplo regime de vinculação. O corpo espectatorial é envolvido neste enlace de visualidades, como se convidado a se implicar - e se perceber - nesta artimanha de olhares. Na elaboração tácita deste acordo de visibilidade, a dimensão relacional

\footnotetext{
15 Do original: "Entiendo la juventud en este texto como una serie de prácticas discursivas que actúan en dos sentidos: (1) como una forma en que cultural e históricamente se establecen modos particulares de ser en relación con el curso del tiempo en las biografías de los sujetos, y (2) como una forma de organizar la reproducción social, particularmente su inserción en ella. (...) Al hablar de 'las y los jóvenes' haré alusión a las formas en que tales procesos se concretan en sujetos particulares, sujetos ubicados en relaciones sociales específicas, con histórias de vida encarnadas en ciertas corporalidades"

${ }^{16}$ Do original: "(...) incursión de la escena trans como parte de la acción política busca no sólo fortalecer la identidad de las implicadas, sino, sobre todo, transformar las concepciones culturales sobre lo trans en las comunidades a las que se llega."
} 
estabelecida com o corpo fílmico se evidencia, abrindo possibilidades de adesão, julgamento, confronto, empatia e valoração da performance de existência que se é dada a ver. Nesse sentido, a trajetória de premiações obtidas pelo filme (Festival de Brasília, Festival Internacional de Cinema de Berlim, Festival Internacional de Cinema de Cartagena, Festival Mix Brasil de Cultura da Diversidade, dentre vários outros) reitera um contrato de leitura dirigido e informado estabelecido com as audiências presumidas.

\section{Incorporações e deslocamentos de uma Bixa Travesty}

Diante das considerações apresentadas até aqui, faremos uma última aproximação teórica-analítica que destaca cenas que nos parecem seminais nas propostas de aproximação que nos guiaram na análise do documentário, de suas implicações contextuais e de suas ramificações corpo-políticas. Como trazido anteriormente, Linda Williams (2004) define a pornografia, o melodrama e o horror como "gêneros do corpo" que, respectivamente, fazem com que o corpo goze, chore e grite. Porém queremos aqui pensar, seguindo a aproximação de Gaines (1999) com o conceito de political mimesis e do documentário aos "gêneros do corpo", o que o documentário implicado faria com o corpo?

Acreditamos que o documentário faça o corpo mover-se, constituindo um espaço de encontro entre diversos fluxos e vivências sensoriais, temporais e diaspóricas. Seguindo as ideias de Greiner (2005) do corpo como o resultado dos cruzamentos entre as informações recebidas do mundo e a negociação das mesmas com as que ali já estão, acreditamos que ao receber as informações presentes no documentário o corpo do telespectador se mova. Mover-se não é trazido aqui em sentido apenas espacial, uma vez que o documentário cria uma afetação que movimenta o corpo de maneira emocional, física e até mesmo espiritual. Assim, acreditamos que, para de fato realizarmos uma pesquisa sobre um documentário, devamos ilustrar os aspectos de (re)apresentação que corroboram com a ideia de movimentação do corpo espectador.

Nesta perspectiva, realizamos um levantamento das cenas do documentário "Bixa Travesty" que, ao (re)apresentar o corpo de Linn da Quebrada, ilustram nosso entendimento de autoria deslocada, promovem um cinema de sujeito/subjetivação e instigam a movimentação do corpo espectador a partir de uma audiovisibilidade implicada. Além disso, traremos na análise uma aproximação às perspectivas de corpo privado, corpo particular e o trânsito entre ambos, suscitadas pelo documentário. Para isto, faremos uma análise audiovisual expandida de seis cenas chave deste documentário, sendo elas: 


\begin{tabular}{|l|l|}
\hline CENA & MINUTAGEM \\
\hline 1 - CORPO & $2 " 59-4 " 20$ \\
\hline 2 - MÃE & $11 " 50-17 " 58$ \\
\hline 3 - BANHO & $17 " 59-19 " 08$ \\
\hline 4 - MÚSICA & $19 " 51-21 " 26$ \\
\hline 5 - SAUNA & $24 " 29-27 " 29$ \\
\hline 6 - HOSPITAL & $49 " 04-56 " 42$ \\
\hline
\end{tabular}

A primeira cena a ser analisada, a qual acreditamos ser primordial para 0 entendimento da potência de Linn da Quebrada frente aos padrões sociais e ao estabelecimento de uma autoria centrada exclusivamente no realizador, é a introdução de Linn, ao se dirigir diretamente com os espectadores enunciando a quebra proposta pelo corpo travesti frente ao monopólio masculino.

Linn nos fala da ação dos homens em armar as tramas sociais e culturais de modo que os privilégios ficassem centrados nos mesmos corpos - em geral um corpo masculino cisgênero, heterossexual, branco, sem deficiências, magro e socialmente situado em classes economicamente privilegiadas; o corpo ao qual Linn e sua rede se opõem. Este corpo estabelecido, como traz Linn, faz com que o feminino entre em uma ação eterna de competição pelos restos - trabalhos, espaços, culturas, imagens que sobram.

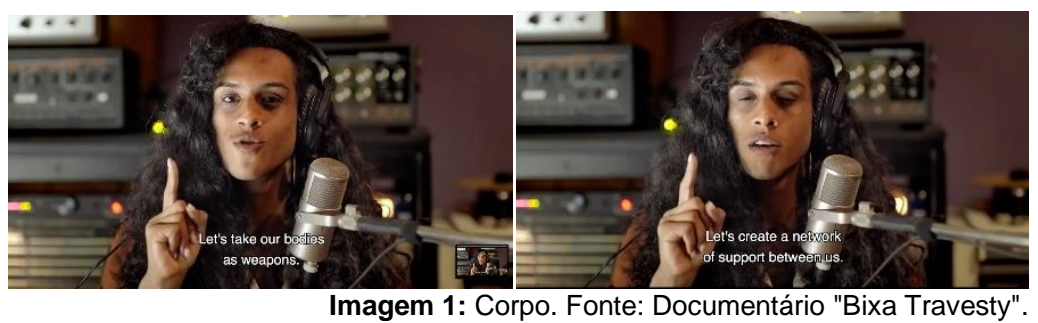


A partir do entendimento da ação das lógicas hegemônicas em excluir os dissidentes, Linn propõe uma subversão da tática de controle, uma subversão que se dará a partir da utilização de táticas ativas e conscientes por parte das mulheridades, da criação de redes de apoio e do uso dos corpos como armas. Essa cena nos ajuda a entender o uso do corpo como arma não apenas no espaço social e cultural; neste caso, essa arma é utilizada para quebrar o consenso audiovisual presente na figura do autorrealizador. O corpo de Linn aliado ao discurso presente nesta cena ajuda a deslocar toda a narrativa e poder do documentário para aquela figura - a figura travesti, negra e política. Assim, a figura de Linn enquanto nuclearidade audiovisual, delimita não apenas o plot da narrativa do documentário, mas nomeia quais serão os espaços ocupados pelo mesmo e como essa ocupação se dará; a plasticidade e a relação com o corpo (re)apresentado de Linn corroboram com a ocupação do espaço do documentário e da mídia, como trazem Zacariotti e Molina (2018) ao analisar demais obras de Linn.

Esta primeira narração ainda localiza o trânsito entre corpo no espaço privado e copo no espaço público/midiático apresentado pelo documentário. A fala de Linn, que acontece logo após uma cena de um show, se dá em um estúdio fechado, em tom intimista e com olhar voltado à câmera/ao espectador. A cena acontece em plano fechado; corpo travesti em evidência. Esta cena dá o tom de todo o documentário. Neste documentário o corpo travesti irá migrar do espaço privado para o espaço público, de modo a ocupar e quebrar com as lógicas de controle social, político e cultural - migração esta iniciada em um plano fechado e marcado pelo olhar de Linn em direção à câmera. Nesta perspectiva de caminho e transposição entre privado e público para entender a movimentação do corpo (re)apresentado para o corpo espectador, a segunda e terceira cenas aqui analisadas nos ajudam a construir um cenário do corpo travesti privado.

Na segunda cena vemos Linn em casa com sua mãe e duas amigas, uma delas a cantora Liniker. Diversas questões são levantadas nesta cena, sendo que, em especial, ao narrar sua relação com os patrões da casa onde trabalha como doméstica, a mãe de Linn expressa gostar muito dos patrões por eles a tratarem bem; Linn completa dizendo "a tratarem como branca", uma localização do corpo de Linn e de sua mãe enquanto corpos negros. Mais à frente, a mãe de Linn a chama de "ele" e Linn a corrige dizendo "ele quem?" E diz que irá tatuar "ela" em sua testa para que ninguém a chame por pronomes masculinos - fato este que se cumpre algum tempo depois.

Nesta cena vemos que o corpo privado de Linn se reafirma enquanto um corpo preto, feminino e travesti; um corpo de potência que circula entre privado e público, entre lar e mídia. Um corpo apresentado em convivência coletiva - mãe e amigas como centro de apoio de transposição do lar para a rua e de afirmação da potência travesti. Imagem e discurso aliados apoiam um deslocamento político, estético e ético. 


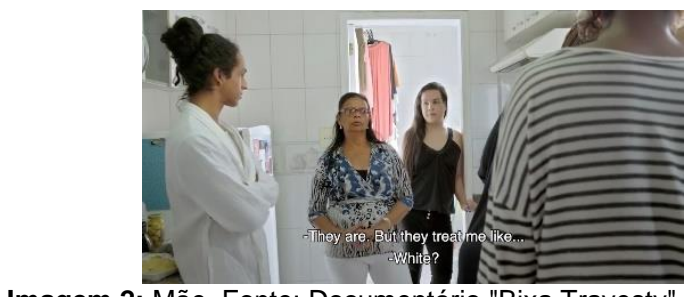

Imagem 2: Mãe. Fonte: Documentário "Bixa Travesty".

Deste modo, o corpo e o discurso de Linn são localizados politicamente e culturalmente durante todo o documentário, sendo que estas cenas no âmbito privado do lar serão o ponto de partida para esta localização de potência. Seguindo esta lógica, observemos a terceira cena.

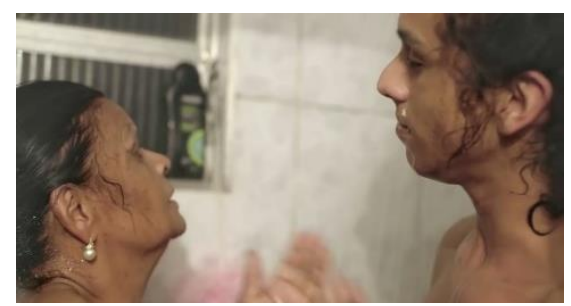

Imagem 3: Banho. Fonte: Documentário "Bixa Travesty".

A terceira cena escolhida para esta análise audiovisual expandida é subsequente à cena anterior; nela vemos Linn e sua mãe tomando banho em um plano fechado com diversos momentos de close. Uma cena que, encadeada à afirmação do corpo como travesti e negro, mostra este corpo. Vemos esta cena como um espaço de localização de poder deste corpo; o documentário não irá apenas falar sobre esse corpo ou essa vivência: ele mostrará e será mostrado através deste corpo.

Ao documentar um corpo feminino dissidente, uma mulher com pau, como traz a música Mulher da própria Linn da Quebrada e nos traz essa cena, o documentário promove um espaço de deslocamento visual no corpo espectador - um deslocamento das concepções estabelecidas do que é um corpo feminino, como reforçado por Linn na cena anterior. Além disso, parte do sentido de movimentação criado pelo corpo de Linn da Quebrada em direção ao corpo do espectador - neste caminho de localizar o documentário como o gênero que move o corpo - se dá por suas performances musicais, sendo estas ligadas à quarta cena selecionada. 

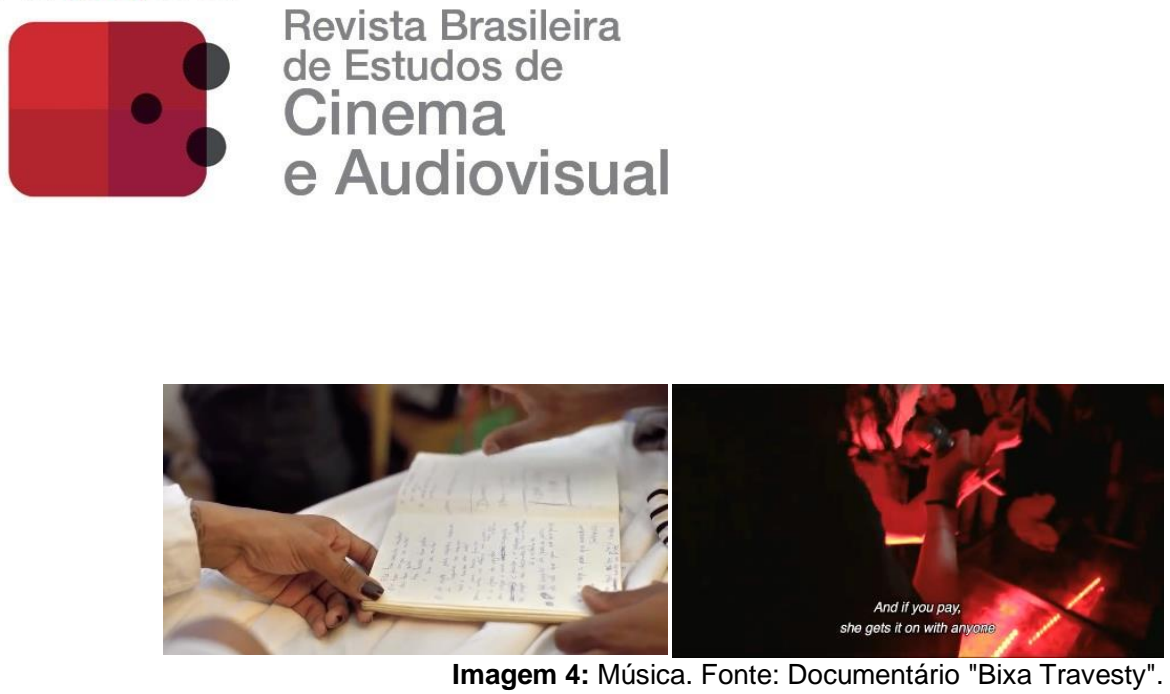

A produção musical de Linn da Quebrada é uma de suas frentes mais conhecidas, de forma que este elemento não ficará excluída dessa aproximação. Nesta quarta cena, vemos a primeira transposição do espaço de expressão privada para um espaço público de maneira mais evidente. A cena é iniciada com Linn e Liniker lendo um antigo caderno onde está escrito um rascunho da letra da música Mulher, cena apresentada em planos fechados pela casa de Linn e por seus objetos de afeto dentro do lar, e é transposta para uma performance de Linn da Quebrada e Jup do Bairro da mesma música em um ambiente de festa, plano geral juntamente com planos médios de modo a apresentar o espaço da festa underground.

A música presente nesta cena, a mesma que se refere ao pau da mulher, contextualiza o corpo travesti como uma potência de vida, uma potência que demarca a produção de conhecimento e de afetos a partir deste corpo dissidente. Desta forma, "Bixa Travesty" nos desloca da imagem da tela e move o corpo espectador ao sentido de uma quebra com os entendimentos de sexo, gênero, arte e também, como principal proposta deste artigo, autoria. Este deslocamento da imagem da tela é agenciado pela própria imagem; ao realizar uma transposição do ambiente do lar para o espaço da festa o documentário move todos os sentidos e corpos a uma autorreflexão existencial em relação aos espaços do público e do privado.

Ao tornar deslocada a lógica de produção do documentário através da corporificação dessa sujeita travesti e negro, "Bixa Travesty" nos possibilita uma primeira visão em relação a um possível cinema de sujeito/subjetivação. Como trazido anteriormente, um cinema que traz o sujeito (re)apresentado como não apenas observado mas como motor de construção de narrativas ou, como aqui proposto, como autor em si/de si - sendo este cinema ilustrado nesta cena pela transposição da música de Linn da Quebrada do ambiente privado para o público. Este deslocamento é também apoiado pelo corpo de outra travesti, Jup do Bairro.

Jup do Bairro, cantora e performer que atuou como backing vocal de Linn, e hoje trilha um caminho musical próprio, lançou na cena artivista de gênero um apelo corpóreo narrativo de engajamento e denúncia das constantes mortes a que são submetidos os corpos dissidentes, pretos e periféricos. Juntas apresentam "TransMissão", no Canal 
Brasil. Nascida e criada na divisa do Capão Redondo, extremo sul de São Paulo, com Itapecerica da Serra, a artista reforça, em suas músicas e videoclipes a força das redes de apoio na existência travesti e periférica em meio às dinâmicas cotidianas de dizimação e silenciamento. Sendo assim, a quinta cena escolhida para análise é uma cena onde, ocupando uma sauna - espaço privado dentro de um ambiente público - Linn e Jup conversam sobre as possibilidades do corpo travesti. Esta cena é apresentada em plano geral de modo a considerar uma ocupação total deste espaço por parte dos corpos travestis de Linn e Jup.

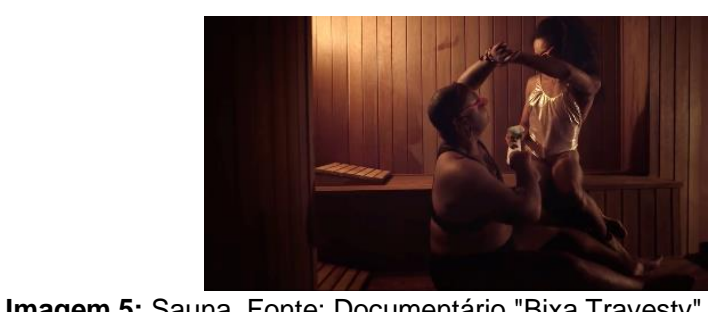

Linn inicia a cena falando sobre como, há tempos atrás, o corpo travesti estava intrinsecamente ligado a um padrão de feminino, padrão este que o corpo dela e Jup se afastam e que, atualmente, está sendo desconstruído por corpos dissidentes. Linn fala também sobre a vontade que ela tem de que, quando as pessoas as olhassem, soubessem que ela não é um homem; mesmo que não soubessem o que ela é, tivessem a certeza que não um homem. Este discurso é associado a uma (re)apresentação do corpo de Linn sob a meia-luz da sauna, imagem com pouca luz sobre o corpo que se afirma feminino enquanto é assombrado por imposições de um masculino.

Em sequência, Jup fala sobre a importância de perceber esse corpo como feminino para a validação desta existência - conhecer o corpo travesti para entendê-lo como um corpo possível e passível de afetos; Jup traz ainda o sofrimento presente nesse corpo que, por trás de toda a política, acaba sendo atingido pelas consequências da marginalização - as consequências de se colocar em jogo. Interessante observar que, ao ressaltar o ponto desse corpo travesti marginal, Jup está de costas para a câmera; uma travesti, preta e gorda (re)apresentada como um corpo parcialmente velado - tanto na imagem e no discurso do documentário quanto no tecido social e cultural.

Os relatos de Linn e Jup nos ajudam a perceber as vontades e experiências desse corpo travesti por elas tem vivenciado, um corpo que não tem necessidade de alcançar um padrão feminino, não quer ser associado ao macho e que tem necessidade de afeto. Um corpo que demanda uma audiovisibilidade protagônica para deslocar concepções de gênero, sexualidade e, em especial neste caso, de travestilidade. Um corpo travesti que ressalta a necessidade de aproximação com o que os corpos dissidentes sentem, 
aproximação esta que muitas vezes é transposta para espaços intrapessoais. Esta cena nos mostra a potência do audiovisível em elucidar o corpo travesti como um corpo passível de afeto; Linn e Jup são símbolo da resistência e de força, porém, essa força não deve ser entendida como a única face, a travesti quer ser amada e quer passar por experiências de afetos. Essa é mais uma movimentação criada no contexto e na visão do espectador a partir da imagem deste documentário; mostrar a travesti como corpo desejante e como possibilidade de afeto.

A última cena, ou grupo de cenas que escolhemos trazer para esta análise é situada nas filmagens que Linn e seus amigos fizeram dela enquanto estava na sua juventude e período de internação para tratamento de um câncer. Esta cena levanta a seguinte questão: a quem pertence este corpo doente? Uma ideia paralela à aqui trazida em relação à sujeita (re)presentado, a quem pertence este corpo representado? Apesar de, em uma primeira visão, entendermos essa posse como da parte que domina a situação, na primeira personificado pelo corpo médico e na segunda pelos diretores, acreditamos que a enunciação fílmica também suscita a perspectiva de este corpo na verdade pertencer à sujeita tratada e representada. Mesmo em um espaço de tensões de poder e dominação, como é o hospital e pode ser o audiovisual, o corpo de Linn se mostra tão consciente ao ponto de não se deixar ser dominado. A fuga da dominação nesta cena é representada pelos vídeos que Linn fazia mesmo quando estava passando pela quimioterapia; como a mesma traz, foi uma época onde ela aprendeu sobre as potências presentes nas fragilidades do corpo. Esses vídeos são transitórios entre closes, planos médios e planos gerais - imagens que bem representam o trânsito do intrapessoal para o interpessoal.

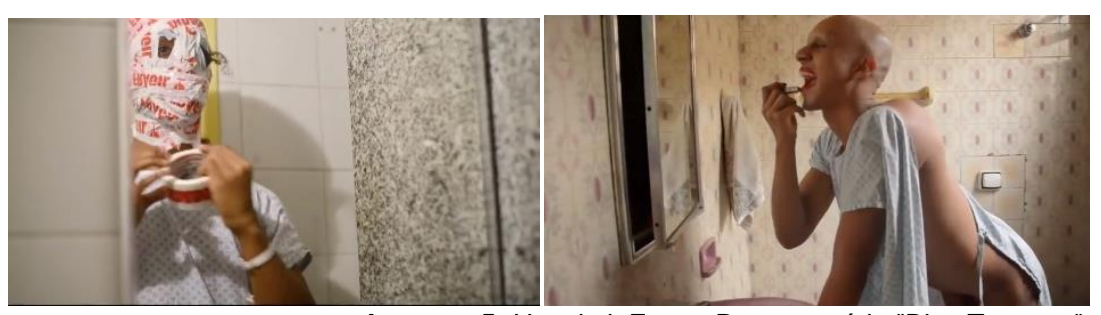

Imagem 5: Hospital. Fonte: Documentário "Bixa Travesty".

Esse corpo que poderia se tornar frágil e passivo frente aos espaços de dominação, médicos e audiovisuais, utiliza de uma potência interna, a partir do conhecimento intrapessoal, para dominar a sua própria narrativa. A narrativa travestida de Linn não se deixa dominar: ela subverte os espaços e se torna dominante. E ainda, esta cena nos mostra o trânsito feito pelas imagens autorais de Linn em um momento privado internação no hospital - para um espaço público - tela do documentário aqui analisado. 
As imagens (re)apresentadas sugerem um corpo que se põe frente ao controle institucional, hospitalar e, neste caso, audiovisual, para deslocar sentidos e posições de poder; o corpo se torna dono de si ao gravar-se no espaço hospitalar e ao transpor estas imagens do espaço privado para o espaço público. Linn da Quebrada se desloca para reinventar a partilha audiovisual.

\section{Considerações Finais}

A partir do aqui apresentado, vemos que "Bixa Travesty" reafirma a potência criada a partir da (re)apresentação de uma sujeita como Linn da Quebrada. Uma sujeita que, ao ser (re)apresentada, leva ao documentário a potência de, ao mover seu corpo, move o corpo fílmico e o corpo espectatorial, deslocando a autoria para os espaços em que se tocam e se afetam subjetividades, de maneira a transformar o documentário em um material de cinema de sujeito/subjetivação. Este deslocamento é tecido na inter-relação do público e do privado - e do movimento entre ambos; deslocamento que busca afetar e movimentar aos corpos através da (re)apresentação, ao invés de simplesmente apresentá-los ou representá-los. E ainda, apesar de ser protagonizado por Linn, este deslocamento é partilhado por Kiko e Claudia de modo a criar uma partilha multi-situada e deslocada do espaço autoral, ou seja, a ruptura é um objetivo comum.

Este deslocamento move em direção ao direito a uma vida cotidiana, a uma existência possível, sendo esta uma pauta política de grande importância nas existências LGBTQIA+, mais evidente ainda quando se trata de corpos transexuais e travestis, corpos e corpas aos quais são, invariavelmente, imputadas localizações aberrantes, de anormalidade compulsória. A própria ação disciplinar, reproduzida e produzida nas dinâmicas de base heterocentrada, cisnormativa, falocêntrica, racista e patriarcal busca de fato impor às dissidências sexuais e de gênero a expropriação do direito a uma vida possível e à equidade que, cabe notar, não significam o mesmo que normatividade.

Sendo assim, o documentário, a partir da (re)apresentação da voz, do corpo e da potência narradora de Linn da Quebrada, faz emergir as experiências de formação cultural e social travesti; faz mover o corpo espectatorial - juntamente com os corpos de Kiko e Claudia - em direção ao movimento cúmplice de crítica social e do questionamento existencial. Algumas críticas ao filme o acusaram de "dicotomizar" e suavizar a força dramática de Linn, de um lado a musa contestadora e iconoclasta, de outro a travesti delicada, acolhida em sua intimidade, deslocada de sua condição estelar ao ser retratada sob a égide de um cotidiano "comum". Todavia, as inversões que atravessam o documentário não deixam de rasurar esta aparente dicotomia, sugerindo 
uma intenção clara de despatologização e enfrentamento da injúria infligida aos dissidentes e às corporalidades precarizadas e desumanizadas.

\section{Referências}

AMARAL, A.; BARBOSA, C.; POLIVANOV, B. "Subculturas, re(a)presentação e autoironia em sites de rede social: o caso da fanpage "Gótica Desanimada" no Facebook". Lumina, v. 9, n. 2, 1 dez. 2015.

AMAYA, José Fernando Serrano. Menos querer más de la vida. Concepciones de vida y muerte en jóvenes urbanos. Bogotá: Siglo del Hombre, 2004.

BAUDRILLARD, Jean. O crime perfeito. Lisboa: Relógio D’Água, 1996.

BERNARDET, Jean-Claude. Cineastas e imagens do povo. São Paulo: Brasiliense, 1985.

Piranha no mar de rosas. São Paulo: Nobel, 1982.

BERNARDET, Jean-Claude e GALVÃO, Maria Rita. O nacional e o popular na cultura brasileira. Cinema. São Paulo: Brasiliense, 1983.

BUTLER, Judith. Corpos que importam: os limites discursivos do "sexo". São Paulo: N1 Edições, 2019.

COLLING, Leandro. "A emergência dos artivismos das dissidências sexuais e de gêneros no Brasil da atualidade". Revista sala preta, v. 18, n. 1, 2018.

ESCOBAR, Manuel Roberto. "La politización del cuerpo: subjetividades trans en resistencia". Nómadas. Bogotá: Universidad Central, abril de 2013.

ESTEVÃO, Andréa Almeida Moura. "Materialidade filmica no documentário: música e imagem tecendo fevereiros". Trabalho apresentado no GT História das Mídias Audiovisuais integrante do 12ํㅡㄹ Encontro Nacional de História da Mídia. ALCAR 2019. Natal, 19 a 21 de junho de 2019.

FREIRE, Marcius. Documentário: ética, estética e formas de representação. São Paulo: Annablume, 2012.

GAINES, Jane M.. "Political Mimesis". In: GAINES, Jane M; RENOV, Michel. Collecting Visible Evidence. Minneapolis: University Of Minnesota Press, 1999. p. 84-103.

GREINER, Christine. O corpo: pistas para estudos interdisciplinares. São Paulo: Annablume, 2005.

HALL, Stuart. Da diáspora. Identidades e mediações. Belo Horizonte: Editora UFMG, 2002.

HARAWAY, Donna. "Saberes localizados: a questão da ciência para o feminismo e o privilégio da perspectiva parcial". Cadernos Pagu, n. 5, 1 jan. 2009, p. 7-41.

MARCONI, Dieison. Ensaios sobre autorias queer no cinema brasileiro contemporâneo. 2020. 141 f. Tese (Doutorado) - Curso de Programa de Pós-Graduação em Comunicação, Universidade Federal do Rio Grande do Sul, Porto Alegre. 
NEVES, Thiago Tavares das. "Fervografia: Fervo, Comunicação e "Bons Encontros" num Show de Linn da Quebrada". In: 42 CONGRESSO BRASILEIRO DE CIÊNCIAS DA COMUNICAÇÃO, 2019, Belém. Anal. Belém: UFPa, 2019. p. 1 - 14.

RANCIÈRE, Jacques. A partilha do sensível: estética e política. São Paulo: Editora 34, 2009.

O espectador emancipado. São Paulo: Martins Fontes, 2012.

RINCÓN, Omar. "Narrativas mediáticas. O cómo se cuenta la sociedad del entretenimiento, col". Estudios de televisión, núm. 23. Barcelona: Gedisa. 2006.

ROCHA, Rose de Melo. "Críticas do audiovisível”. RuMoRes, v. 13, n. 25, 13 jun. 2019, p. 50-65.

Entrevista "Artivistas de gênero e a transformação pela música". <http://www.generonumero.media/entrevista-artivistas-de-genero-e-transformacaopela-musica/>. Acesso em: 12 ago. 2020.

"Eram iconoclastas nossos ativistas? A representação na berlinda e as práticas comunicacionais como formas (políticas) de presença". In: JESUS, Eduardo et al. (orgs.). Reinvenção comunicacional da política: modos de habitar e desabitar o século XXI. Brasília: Compós, 2016. p. 31-46

Estética da violência. Por uma arqueologia dos vestígios. Tese (doutorado). ECA/USP, São Paulo.

; REZENDE, Aline. "Diva da sarjeta: ideologia enviadescida e blasfêmea pop-profana nas políticas de audiovisibilidade da travesti paulistana Linn da Quebrada". Contracampo, Niterói, v. 38, n.1, abr-jun 2019, p. 22-34.

SAFATLE, Vladimir. Cinismo e falência da crítica. São Paulo: Boitempo, 2008.

SPINOZA, Benedictus. Ética. Belo Horizonte: Autêntica, 2008.

SONTAG, Susan. Contra a interpretação. Porto Alegre: L\&PM, 1987.

TAYLOR, Diana. The archive and the repertory: performing cultural memory in the Americas. Durham: Duke University Press, 2003.

VIEIRA JR., Erly. Realismo sensório no cinema contemporâneo. Vitória: EDUFES, 2020.

VIDARTE, Paco. Ética Bixa: proclamações libertárias para uma militância lgbtq. São Paulo: N-1 Edições, 2019.

WILLIAMS, Linda. "Film bodies: gender, genre and excess". In: BAUDRY, L.; COHEN, M. (Org.). Film theory and criticism. Oxford: Oxford University Press, 2004.

ZACARIOTTI, Daniel José de Castro Silva; MOLINA, Anelise Wesolowski. "O Sexo Travesti como um Fator Político". In: ALCÁNTARA, Manuel (Org.) Estudios de Género. Salamanca, p. 316-326. Ediciones Universidad de Salamanca, 2018. 